\title{
Long Storage as Water Source during Dry Period for Sarawak River Basin
}

\author{
Nyambar, S. ${ }^{1}$ and Bong, C.H.J. ${ }^{2}$
}

\begin{abstract}
The recent drought in August 2009 which was triggered by the El Nino phenomenon had affected Kuching city to the extent that the city was facing critical shortage of water supply. In this study, the daily water demand for Kuching city was determined based on two major usages which were treated water demand for water supply production and for the flushing operation by the barrage in Sarawak River Basin for a selected year. These water demands were compared with the available supply from Sarawak River to determine the amount of water as storage to be prepared for critical shortage during the drier period. The results shows that the total maximum, average and minimum daily water demand for Sarawak River Basin are 8,715.264, 3,812.516 and 82.946 cumec.day respectively. The maximum daily demand was compared with the water supplied by Sarawak River Kiri at Kpg. Git station and from the flow mass curve; the needed storage is approximately 100 cumec.day for the critical period of May to October. A preliminary design for long storage has also been proposed to store water during the wet season to be used during the dry period.
\end{abstract}

Keywords: Long storage, Maximum Daily Demand, Sarawak River Basin, Water Supply

\section{INTRODUCTION}

CARAWAK River Basin is one of the important river basin in the state of Sarawak due to the establishment of Kuching city, the capital of Sarawak within the basin. The area of Sarawak River Basin is about $2375 \mathrm{~km}^{2}$ and the total length of the main river is $120 \mathrm{~km}$ (see Figure 1). The main river consist of two principal tributaries, which are Sarawak River Kiri and Sarawak River Kanan which meet some $34 \mathrm{~km}$ upstream of Kuching city. Kuching city currently has a population of about 500,000 and the main source of water supply for municipal use is from Batu Kitang Treatment Plant. Beside for municipal water demand purpose, water is needed for flushing operation for the barrage and to maintain the minimum level in the river for navigation purposes.

As Kuching city faced rapid urbanization, there is concern on whether the current supply by Sarawak River is enough to cater for the increasing demands. The currently under construction Bengoh Dam is hope to be able to produce about 2,047 MLD of raw water by the year 2030 when the demand for water supply in Kuching is expected to be 2,000 MLD by then [1]. However, with the current trend of weather pattern such as the recent drought in August 2009 where Kuching is facing water rationing as the shortage becomes critical [2] and the increasing flooding occurrence during the wetter months of December to February, it is critical to make sure that the water supply is sufficient to fulfill the water demand of the city throughout the year.

In order to address the problem of probable water shortage during the drier months, one of the possible solutions is to have a long storage in the basin. This long storage will store water during the wetter months to be used during the drier months such as the ones in Bojongsari and Margawati in Indonesia [3]. Long storage is an easy method to overcome water crisis because it is cheaper in cost and less environmental problems than constructing a dam. The maintenance and operation of long storage are also less expensive and easy to carry out than a dam beside the capability of long storage of various functions for daily usage. Thus, this paper will present the findings of water supply and demand analysis for a selected year in Sarawak River Basin and explore the possibility of having a long storage and the preliminary design of this storage in the basin to address the issue of water shortage in the basin during the drier months.

\section{DATA COLLECTION AND ANALYSIS}

Data for water demand consist of water production and consumption were taken from Batu Kitang Treatment Plant while for flushing operations by the barrage; the data were collected based on the flushing operations schedule (for this study, all the data collected were for the year 2001). Water demand was calculated based on the total of monthly discharge for treated water demand and flushing water demand. Three conditions were taken into account for this purpose, i.e. the maximum, minimum and mean demand for both water production and flushing operations.

\footnotetext{
${ }^{1}$ Undergraduate student, Faculty of Engineering, Universiti Malaysia Sarawak, 94300 Kota Samarahan, Sarawak, Malaysia; e-mail: vest_85@yahoo.com

${ }^{2}$ Lecturer, Faculty of Engineering, Universiti Malaysia Sarawak, 94300 Kota Samarahan, Sarawak, Malaysia;

e-mail: bhjcharles@feng.unimas.my
} 
As for water supply, data for water levels based on daily mean stage level were collected for Git station and Buan Bidi station which are located on Sarawak River Kiri and Sarawak River Kanan respectively. These water level data were converted into discharges data based on the rating curve formula provided by the Drainage and Irrigation Department, Sarawak. The yield or available supply of the river was determined from the discharge data.

From both these water demand and supply data, flow mass curve diagram were plotted for cumulative discharge of water demand versus cumulative discharge of available water supply. From the flow mass curve diagram, the required storage for the river was determined based on the maximum difference between supply and demand volumes over the dry season [4].

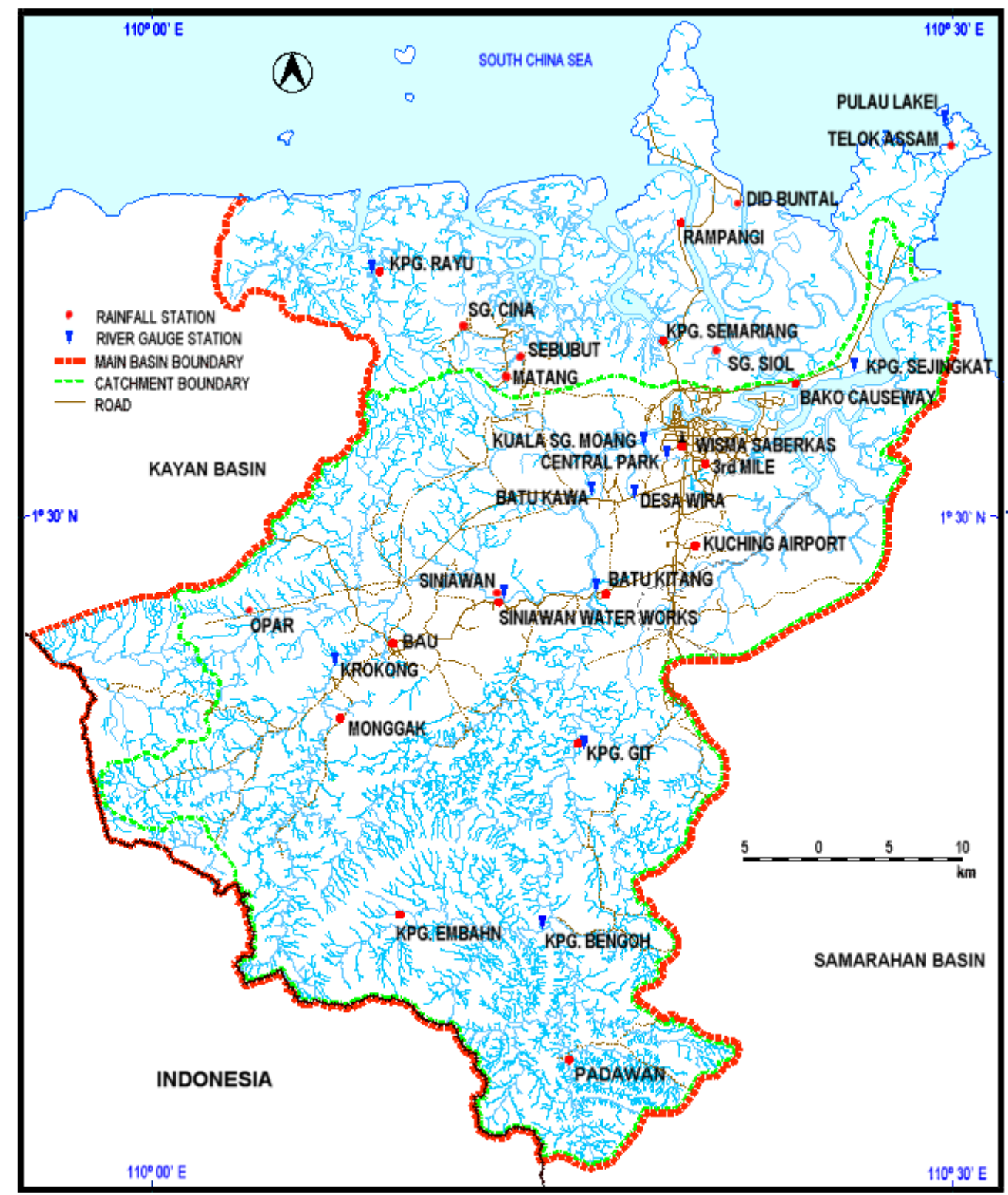

Figure 1 Sarawak River Basin [5]

\section{FINDINGS AND DISCUSSION}

The plot of cumulative discharge for available water supply for both Buan Bidi and Git station are as shown in Figure 2 . The cumulative water demand curves for the three conditions of maximum, minimum and mean are also plotted on the same graph for the available supply. Maximum discharge of water demand consists of maximum capacity of production from Batu Kitang Treatment Plant and the maximum discharge during flushing operation at Kuching Barrage by assuming that the daily maximum demand are constant for the whole month throughout the year. Average or mean demand consists of the mean daily production for water production while the minimum water demand consists of the lowest total monthly discharge for water production for the selected year. Results from these plots shows that for the selected year of 2001, the water supplied by both the Sarawak River Kiri (Git) and Sarawak River Kanan (Buan Bidi) is sufficient to cater for the total water demand for that year. This is evidence from the plots where the cumulative discharge for supply for Git station is always higher than the required cumulative demand. However, to determine that whether there is any critical period in that year where the water supplied will be less that the demand, a flow mass curve for maximum demand as shown in Figure 3 is plotted. 
UNIMAS E-Journal of Civil Engineering, Vol. 1 (2)/April 2010

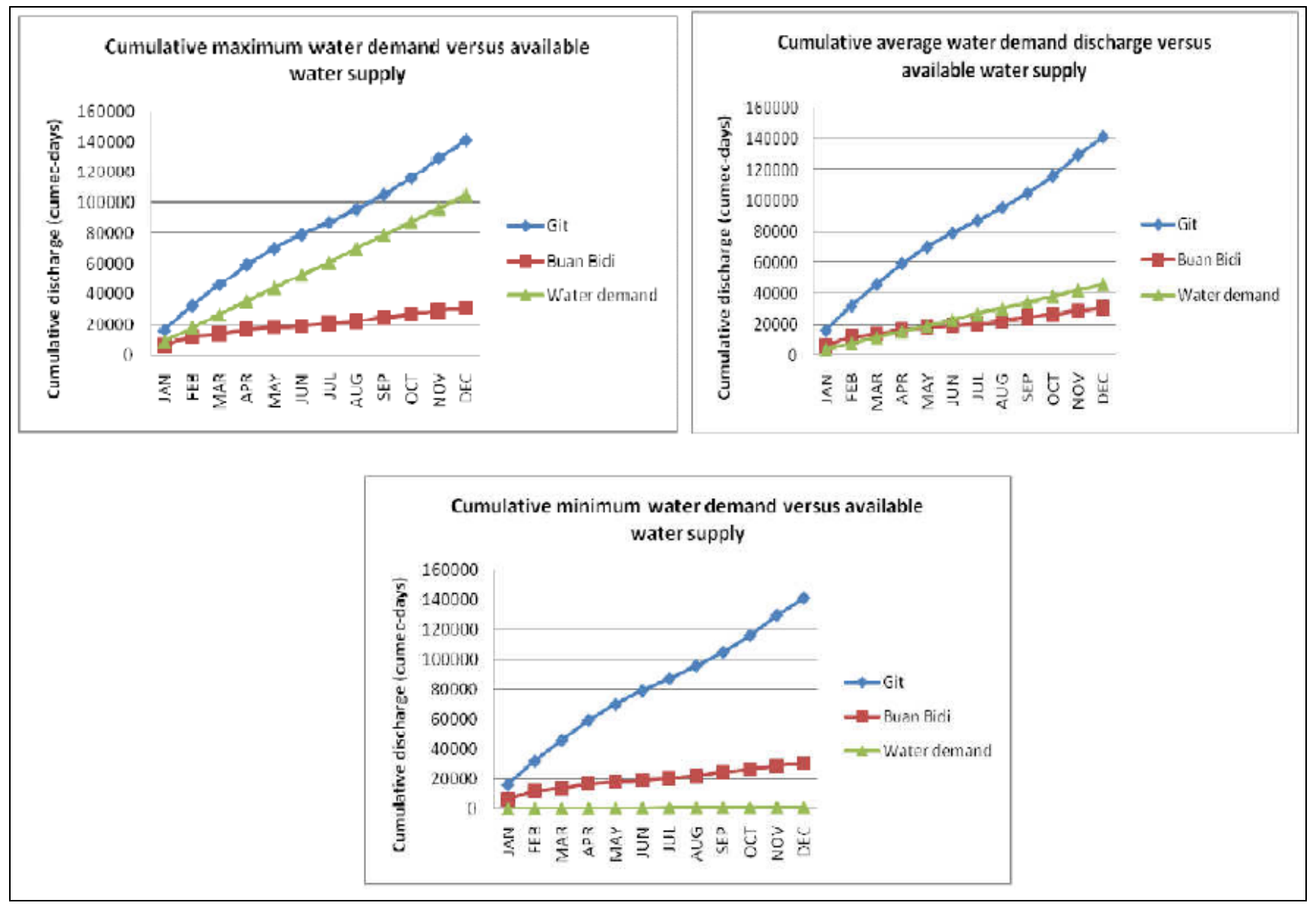

Figure 2 Comparison between maximum, average and minimum water demand and available supply for Sarawak River Basin for the year 2001

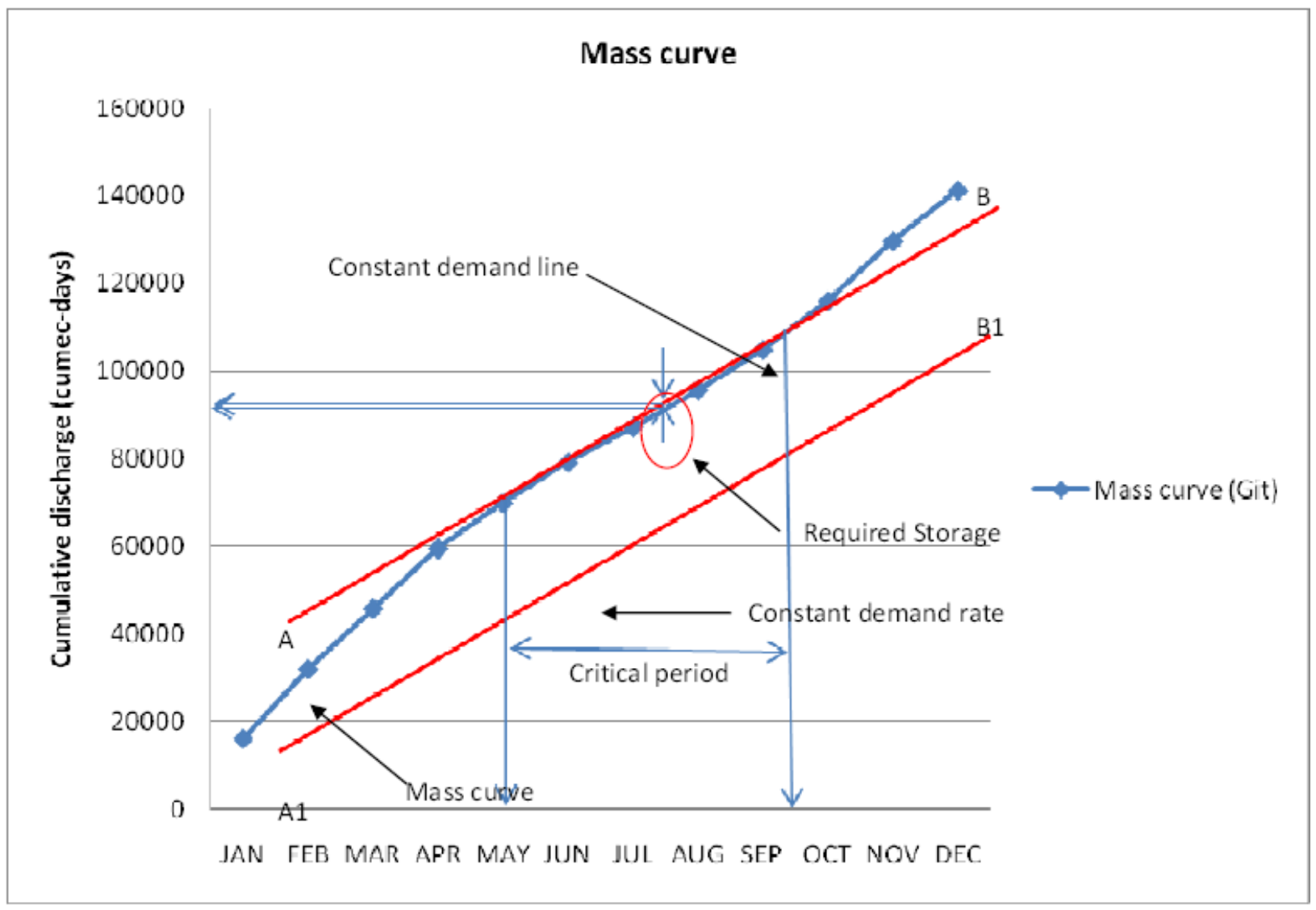

Figure 3 Flow mass curve of maximum demand for Sarawak River Basin for the year 2001

From Figure 3, the flow mass curve for available water supply at Git station is plotted and a constant demand line based 
on the maximum demand is drawn tangentially to the mass curve at the high point on the ridge. The required storage is the maximum difference between the constant demand line and the mass curve. In this case the maximum difference happened in the month of August 2001 and the required storage for this critical period is 100 cumec.day or $8,640,000 \mathrm{~m}^{3}$. The plot also shows the critical period which starts in May 2001 and ended roughly in October 2001.

To store the required water for critical period, the location for a long storage for Sarawak River Basin is as proposed in Figure 4. The suitable location for the long storage had been selected based on the river cross sections and the volume of water the chosen stretch of river could store. The selected location is situated at Sarawak River Kanan due to the factor of existing structures on Sarawak River Kiri (Batu Kitang Submersible Weir and Bengoh Dam) which would interfere with the operation of the proposed long storage. Table 1 shows the proposed preliminary design of the long storage while Figure 5 shows the layout of the proposed checkgates structures for the long storage. The checkgates will have weirs on both sides so that water will flow through these weirs into the existing river system once the maximum level of storage is achieved. During critical period, water will be released from the long storage through these checkgates; thus providing enough water to meet the demand during the maximum critical period of the year.

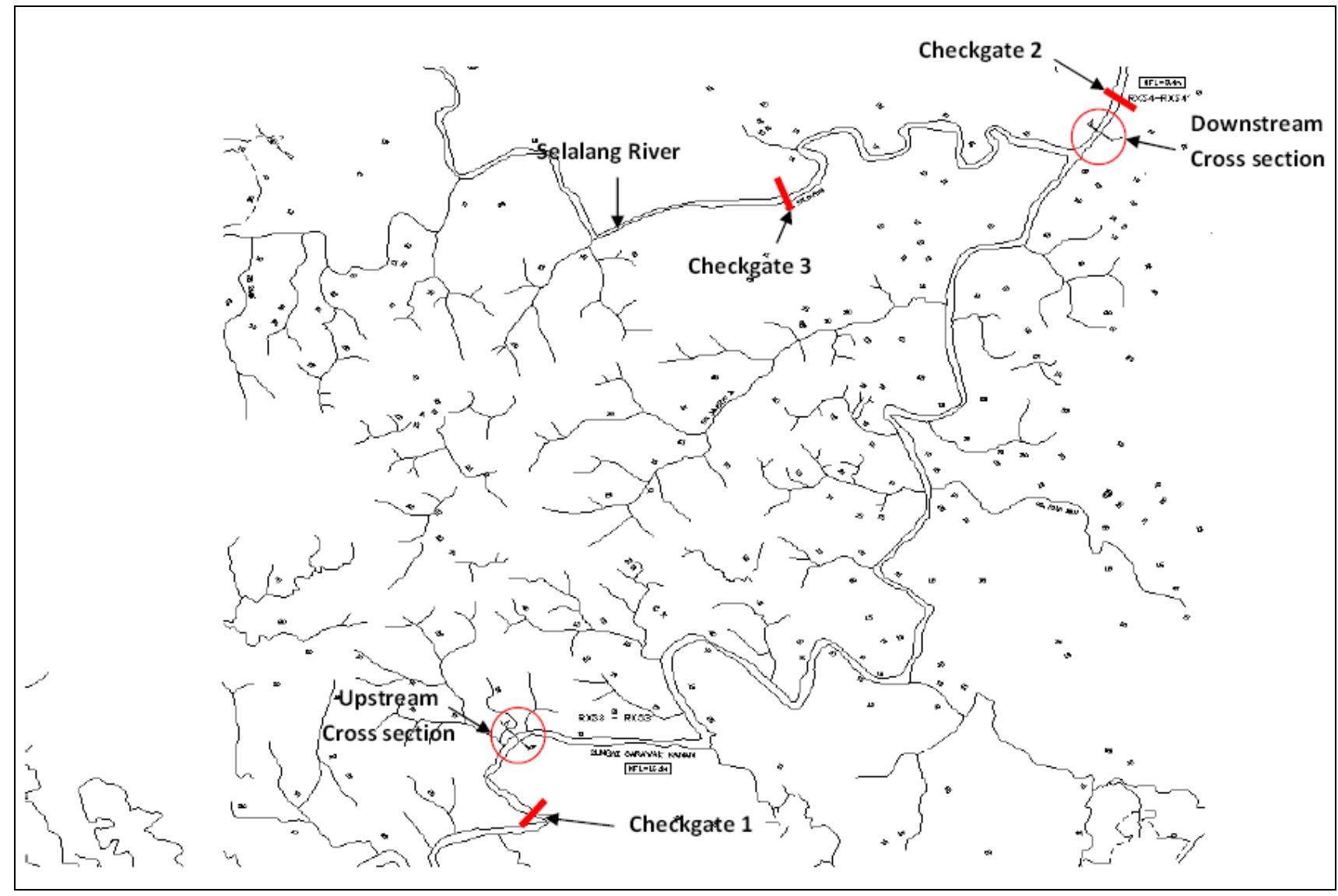

Figure 4 Location of proposed long storage at Sarawak River Kanan

Table 1 Proposed preliminary design for the long storage at Sarawak River Kanan

\begin{tabular}{|l|l|}
\hline Capacity & $\pm 8,700,000 \mathrm{~m}^{3}$ \\
\hline Proposed long storage length & $\pm 14,500 \mathrm{~m}$ \\
\hline Upstream width & $\pm 149.876 \mathrm{~m}$ \\
\hline Downstream width & $\pm 154.665 \mathrm{~m}$ \\
\hline Proposed long storage width & $\pm 100 \mathrm{~m}$ \\
\hline Proposed long storage height & $\pm 6 \mathrm{~m}$ \\
\hline
\end{tabular}




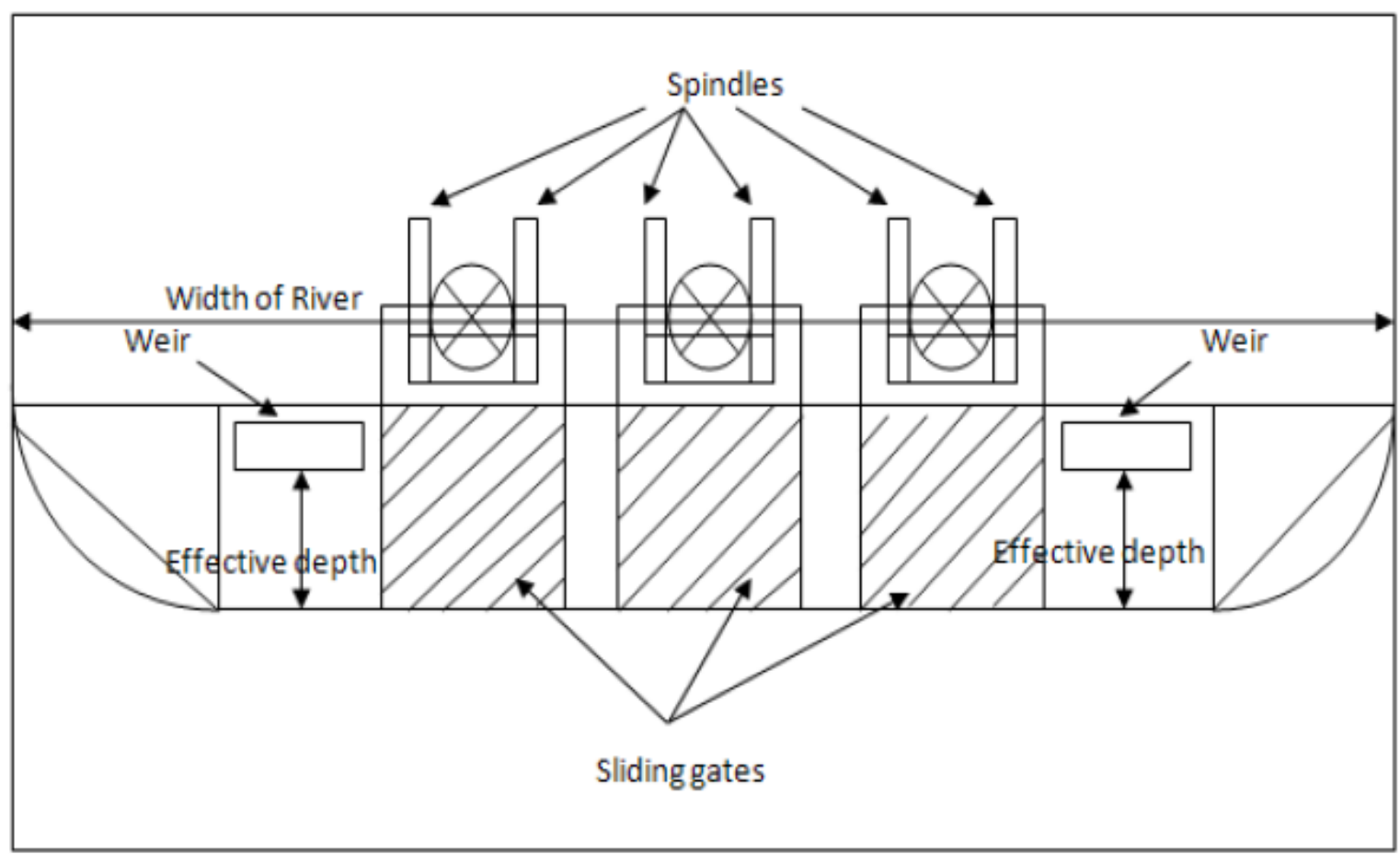

Figure 5 Layout of the proposed checkgates structures for the long storage at Sarawak River Kanan

\section{CONCLUSIONS}

The required water demand and the supply needed to meet these demand in Sarawak River Basin for the year 2001 has been presented in this study. From the findings, the water supplied by both the Sarawak River Kiri (Git) and Sarawak River Kanan (Buan Bidi) is sufficient to cater for the total water demand for the year 2001. However a further analysis on the flow mass curve has shown that there is a critical period for the year between the months of May to October and the maximum storage needed to cater for the needs during this period is 100 cumec.day or $8,640,000 \mathrm{~m}^{3}$. A possible location and preliminary design for a long storage to store this amount of water has been proposed on Sarawak River Kanan.

\section{ACKNOWLEDGEMENT}

The authors would like to thanks the Drainage and Irrigation Department, Sarawak; Kuching Water Board and Sarawak River Board for their full cooperation in providing the required data for this project.

\section{REFERENCES}

[1] The Borneo Post. (2009, December 22). Two more dams needed to supply raw water. [Online]. Available: http://www.theborneopost.com

[2] The Star. (2009, August 9). Water rationing in Kuching as shortage becomes critical. [Online]. Available : http://www.thestar.com.my

[3] M. Barmawi, 'Long Storage as water source during dry season in West Java', presented at River and Development, Bali, Indonesia, April 25 - 27, 2007.

[4] K. Subramanya, 'Engineering Hydrology', $2^{\text {nd }}$ ed.,Singapore : McGraw-Hill, 2007, pp. 158 - 159.

[5] Drainage and Irrigation Department, Sarawak official website. [Online], Available : http://www.did.sarawak.gov.my 